\title{
Stereotactic linac radiosurgery and hypofractionated stereotactic radiotherapy for pediatric arteriovenous malformations of the brain: experiences of a single institution
}

\author{
Slawomir Blamek • Dawid Larysz • Leszek Miszczyk \\ Received: 28 October 2012 / Accepted: 15 November 2012/Published online: 8 December 2012 \\ (C) The Author(s) 2012. This article is published with open access at Springerlink.com
}

\begin{abstract}
Purpose The aim of our study was to evaluate treatment results and toxicity of stereotactic irradiation for arteriovenous malformations (AVMs) in children.

Methods A group of ten consecutive children (four boys and six girls) irradiated between 2002 and 2010 at our institution was included into the study. The mean age at the time of treatment was 15.4 and ranged between 8 and 18 years. There were two Spetzler-Martin grade IV, four grade III, and four grade II lesions. Mean AVM volume was $13.2 \mathrm{~cm}^{3}$ and varied from 0.6 to $36.8 \mathrm{~cm}^{3}$. In five patients, the planned dose of 16-20 Gy was delivered in single fraction, in five the total dose of 16-24 Gy was delivered in two to three fractions. One patient was reirradiated with a dose of $15 \mathrm{~Gy}, 7$ years after the initial treatment.

Results The median follow-up was 38.5 months. The treatment resulted in total obliteration in eight patients and partial in one. The median time to obliteration was 22 months; actuarial total obliteration rates were 20, 54, 54 , and $83 \%$ after $1,2,3$, and 4 years of follow-up, respectively. No patient bled after the treatment. In one patient, new epileptic seizures developed after the treatment; in magnetic resonance imaging, focal necrosis was revealed. In five patients, asymptomatic imaging abnormalities were seen during follow-up.
\end{abstract}

S. Blamek $(\bowtie) \cdot$ D. Larysz $\cdot$ L. Miszczyk

Department of Radiotherapy, Maria Skłodowska-Curie Memorial

Cancer Center and Institute of Oncology, Gliwice Branch,

ul. Wybrzeże AK 15,

44-100 Gliwice, Poland

e-mail: blamek@gmail.com

D. Larysz

Department of Neurosurgery, Silesian University of Medicine,

ul. Medyków 14,

40-752 Katowice, Poland
Conclusions Stereotactic radiotherapy appears to be an effective method of treatment for pediatric AVMs, the patients however require meticulous follow-up because of relative high incidence of radiation-induced imaging abnormalities.

Keywords AVM $\cdot$ Hemorrhage $\cdot$ Obliteration $\cdot$ Radiobiology

\section{Introduction}

Arteriovenous malformations (AVMs) are considered congenital lesions of the brain. They are however diagnosed mainly in patients at their $30 \mathrm{~s}$ or $40 \mathrm{~s}$, whereas the incidence in children is lower. Angiogenic potential of AVMs in children can be responsible for systematic growth of the lesions during childhood and adolescence and is proposed to be one of the reasons of relatively low number of lesions diagnosed at young age [17, 23, 37]. The intensity of angiogenesis seems to decrease over time and probably is negligible in the mature organism. There is however some evidence that certain factors, like the material used for embolization or transient hypoxia caused by the procedure itself, can stimulate angiogenesis in otherwise mature AVMs [2, 39].

There is still a widespread opinion that the mainstay of the treatment is microneurosurgical removal of the AVM. There is however an increasing number of evidence that stereotactic radiosurgery can be considered as a primary treatment modality in children and the number of treatment-related complications can be even lower than in adults [30]. Usually, the lesions that cannot be surgically removed are treated with embolization or stereotactic radiosurgery often associated with endovascular procedures [24]. Embolization in certain cases however may result with subtotal occlusion of the nidus leaving some portions of the lesion connected to the circulation and thus, posing a 
risk of rupture [26, 35]. Nevertheless, curative embolization can be attempted with good results in carefully selected patients with small- or intermediate-sized AVMs [42].

The treatment of arteriovenous malformations in children is a special challenge. Not only due to angioproliferative potential of the lesion which can attenuate the results of the treatment but also due to higher risk of bleeding than in adults, substantial death rate, and potential late sequelae of the treatment $[22,28,43]$. There are also concerns that exposure of the immature brain to ionizing radiation can affect the intellectual abilities or cause neurological damage [43]. Moreover, AVMs in children are more often localized in deep structures or eloquent regions of the brain than in adults which makes the surgical treatment more difficult or even impossible.

Discussing the indications for radiosurgery of AVMs in children, it is important to note that death rate due to cerebral hemorrhages in children is very high and ranges between 6 and $38 \%$ according to various sources $[4,6,40]$. AVM rupture is one of the most frequent reasons of hemorrhagic stroke in children and is responsible for $14-56 \%$ of all strokes in this age group $[4,6,10,12,16,40]$. Cumulative risk of bleeding from an AVM can be calculated from the Brown formula and is directly associated with age of the patient [7]. It means that AVM diagnosed in a child almost inevitably leads to and intracranial hemorrhage (ICH), and thus, should be treated. The available choices are microneurosurgery, stereotactic radiosurgery, and embolization. Sometimes satisfactory results can be obtained only with a combination of two or even three methods.

In this report, we review our experience with linear accelerator-based radiosurgical treatment of pediatric AVMs. We focus on obliteration rate, prevention of intracranial hemorrhage, side effects of the treatment, and radiation-induced alterations in imaging studies.

\section{Material and methods}

A group of ten consecutive children (four boys and six girls) irradiated between 2002 and 2010 at our institution is analyzed in the current study. The mean age at the time of treatment was 15.4 and ranged between 8 and 18 years. There were two Spetzler-Martin grade IV, four grade III, and four grade II lesions. The mean AVM volume was $13.2 \mathrm{~cm}^{3}$ and ranged between 0.5 and $36.8 \mathrm{~cm}^{3}$. For all lesions, the modified radiosurgery-based AVM score defined as $\mathrm{AVM}$ score $=0.1 \times \mathrm{AVM}$ volume $+0.02 \times$ patient's age $+0.3 \times$ location (location is a two-tiered variable and has a value of 1 for lesions located in thalamus, basal ganglia, and brainstem; for other locations, the value is 0 ) was calculated [33]. The mean and median modified radiosurgery-based AVM score was 1.69 and 1.7, respectively, and ranged between 0.41 and 4.26. All AVMs were located supratentorially, three of them intra- or periventricularly. Six patients presented with hemorrhage, three with epileptic seizures, and one only with impaired consciousness. One patient had bled twice before the treatment was started. Two had symptoms of hemiparesis after ICH. One patient underwent a surgical procedure (subtotal removal of the nidus) before irradiation. We decided to include in this report patients treated both with stereotactic radiosurgery and hypofractionated stereotactic radiotherapy because of low number of children irradiated for cerebral AVMs and in order to allow direct comparison of the two fractionation regimens. The clinical and treatment characteristics of each patient are presented in detail in Table 1 in order to facilitate potential future meta-analysis of the results of stereotactic irradiation of pediatric AVMs.

All patients were irradiated with a linear accelerator with a micro-multileaf collimator used for field shaping. The head was immobilized in a thermoplastic mask designed for stereotactic treatment and a relocatable stereotactic frame was used in all cases to define external coordinates. Treatment planning was based on computed tomography performed with the relocatable stereotactic frame, magnetic resonance (MR), and magnetic resonance angiography images. In no case anesthesia was required. The dose was specified at the isocenter and the planning was optimized to encompass the lesion with $95 \%$ isodose. In case of lesions adjacent to organs at risk, like the optic pathway or brainstem, a focal drop to $90 \%$ of the prescribed dose was accepted. In five patients, the planned dose of 16-20 Gy was delivered in a single fraction, in five the total dose of 16-24 Gy was delivered in two to three fractions. One patient was reirradiated with a dose of $15 \mathrm{~Gy}, 7$ years after the initial treatment. Apart from the use of stereotactic frame, the correct position of the patient was additionally verified with the on-board imaging device immediately before irradiation to account for possible positioning inaccuracies that may occur when stereotactic mask and relocatable frame are used instead for invasively fixated stereotactic frame. Actuarial obliteration rates were calculated with Kaplan-Meier method. Due to small number of patients in our series, subgroup comparisons were made with Fisher's exact test for small samples.

\section{Results}

The median follow-up time was 38.5 months and ranged from 13 to 120 months. The treatment resulted in total obliteration in eight patients and partial in one; in one, no response to treatment was seen. One patient was irradiated twice because of incomplete obliteration after the first procedure. The second treatment was performed 7 years after 


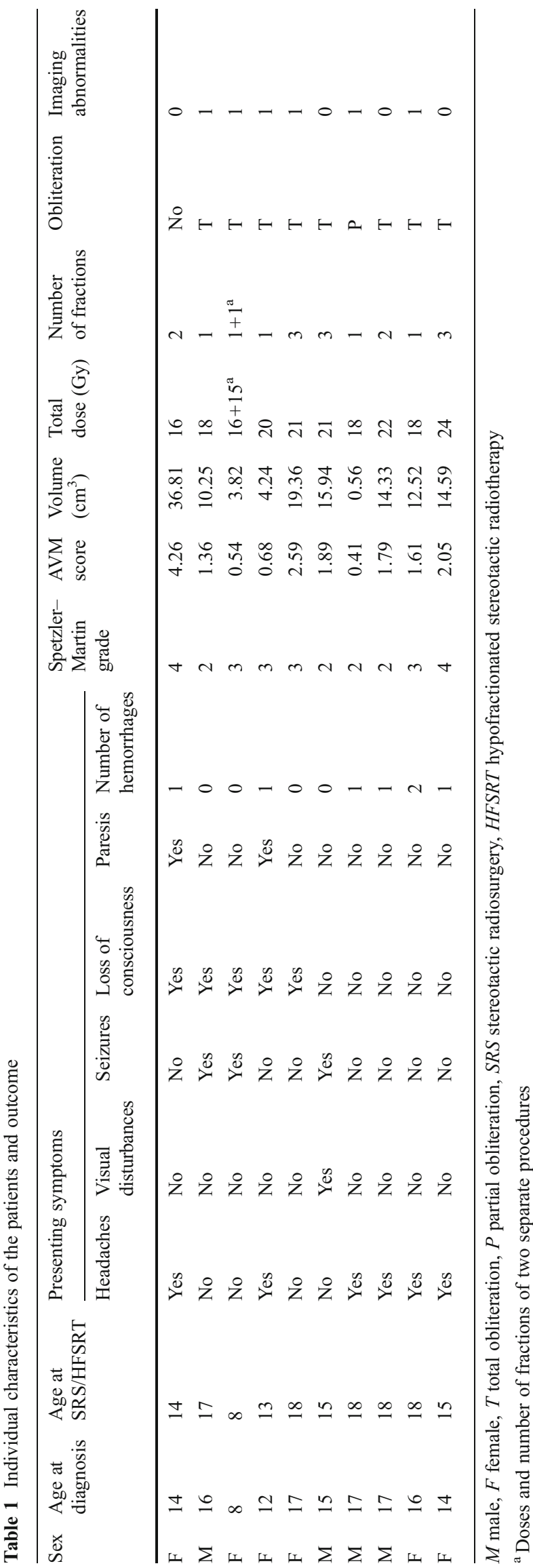

the first irradiation and resulted with total obliteration of the nidus. The median time to obliteration was 22 months. Crude total obliteration rate was $80 \%$. Actuarial total obliteration rates were $20,54,54$, and $83 \%$ after $1,2,3$, and 4 years of follow-up, respectively. Crude response rate (total and partial obliterations) was $90 \%$. Actuarial treatment response rates were $20,54,65$, and $89 \%$ after $1,2,3$, and 4 years of follow-up, respectively. The only patient who did not respond to the treatment had the largest lesion $\left(36.8 \mathrm{~cm}^{3}\right)$ and was irradiated with 16 Gy delivered in two fractions because of the size of the nidus and critical location, adjacent to the brainstem and optic pathway. In this patient, reirradiation of the nidus is considered.

No patient bled during 42.5 patient-years of observation; therefore, bleeding risk after treatment could not be reliably calculated. In one patient, new epileptic seizures developed after the treatment. MR imaging revealed symptoms of demyelination around the irradiated nidus. The seizures gradually resolve and currently she experiences only an aura in approximately every 6 months. In one patient, after the second treatment, an asymptomatic focal necrosis was revealed on MRI which partially resolved after another year of follow-up.

In five patients, asymptomatic imaging abnormalities were seen during follow-up. The imaging abnormalities were defined as T2 or FLAIR hyperintensity or T1 hypointense areas. Due to low number of patients in the study, no detailed statistical calculations could be made. According to results of the Fisher's exact test, no apparent dependence of obliteration on AVM volume, Spetzler-Martin grade (2 vs. $>2$ ), dose ( $<20$ vs. $\geq 20$ Gy), or AVM score $(<1.7$ (median value) vs. $\geq 1.7$ ) could be identified. Both single fraction treatment and hypofractionated stereotactic radiotherapy resulted with comparable number of obliterations $(p=0.33$ and $p=0.6$ for total and total + partial obliterations, respectively, Fisher's exact test). Similarly, no apparent association of the dose, fractionation regimen, and volume irradiated and the incidence of imaging abnormalities could be seen.

\section{Discussion}

This is a series of ten children irradiated for cerebral AVMs with crude obliteration rate of $80 \%$ and no bleeding observed after the treatment. Hemorrhage form a ruptured AVM is the most frequent symptom leading to the diagnosis of the malformation both in adults and children [19]. Nevertheless, both death rate and the risk of permanent neurological sequelae are higher in children [5, 9]. These data show that the potential risk associated with exposition of the immature organism for ionizing radiation is overcome by expected elimination of the risk of bleeding. In our series, no bleeding occurred after the treatment which is in line with 
the results reported by Nicolato et al. and compares favorably with other series reporting the annual bleeding hazard rate of $1.3-4.7 \%$, to even $9.1 \%$ in the first and $13.6 \%$ in the second year of follow-up [8, 22, 29, 31, 44]. According to the literature, malformations in the posterior fossa are of special concern because the risk of death following rupture can approach $42-57 \%$ and that location is much more frequent in children than in adults [15, 21, 27, 34]. In our series, no lesion was localized in the infratentorial space. It can be explained by selection bias resulting from relative low number of children referred to radiosurgery for AVMs in our country and limited number of patients included into the study.

Crude total obliteration rate of $80 \%$ in our series is among the highest of reported by other authors $[8,18,22$, $31,32,36,44]$. Better results can be obtained by applying higher doses but this carries a risk of increasing the complication rate. Doses of 24-25 Gy specified on the surface of the lesion allow for obliteration rate approaching $100 \%$ but at the cost of unacceptable risk of serious complications. In the series published by Mirza et al., the incidence of adverse effects after delivery of 24-25 Gy in single fraction was as high as $50 \%$ [28]. Actuarial obliteration rate was stable in the second and third year of follow-up; this phenomenon however can be explained as a statistical artifact resulting from low number of patients in our series.

Total obliteration is considered the ultimate goal of radiosurgery for cerebral AVMs. Nevertheless, literature data indicate that subtotally obliterated malformations possess a negligible risk of bleeding and eventually obliterate in most cases [22]. In our opinion, the primary goal of radiosurgery should be elimination of the risk of bleeding but not necessarily complete obliteration without early draining veins on angiography. Pertinent aiming at complete radiological obliteration by application of higher doses increases the risk associated with the treatment without apparent profits for the patient because the risk of hemorrhage is not further reduced in a significant way $[1,22]$.

The probability of obliteration was not directly associated with the fractionation regimen. Both single fraction treatment and hypofractionated stereotactic radiotherapy yielded comparable rates of obliterations. Satisfactory results of hypofractionation in children could be associated with biological features of an immature AVM. Higher mitotic and metabolic activity of the cells can possibly result with faster and more efficient production of myofibroblasts responsible for subsequent obliteration of the nidus. This can be true even after stimulation with lower single doses, assuming that fraction dose is sufficient for triggering the effect and total dose applied is within the therapeutic range. There is some evidence that younger patients respond better to radiosurgery, not only when comparing children and adult population, but even if we consider only the group of pediatric patients $[31,34,36]$. The difference in biological features between adult and pediatric AVMs was already proposed in the literature and confirmed in recent studies, but the exact reason of the specific behavior of the pediatric AVMs is still to be explained [25, 31]. Vascular proliferation and expression of VEGF and its receptors observed in AVMs, de novo formation of the lesions, and low prevalence of AVMs in infants suggest that these lesions in young age can have greater mitotic potential resulting with greater alpha/beta ratio than that reported in the adult population $[3,11,13$, 17, 23, 38, 39]. Estimations of alpha/beta ratio for AVMs yielded the value of 1.2-3.5 Gy, characteristic for nonproliferating, late responding tissues [20]. Analysis of smaller lesions however suggested that they can respond somewhat different and the alpha/beta ratio can approach 5-6 Gy which can be the rationale for hypofractionated regimens [20]. If pediatric AVMs present similar propensities, higher obliteration rates than in adults after hypofractionated stereotactic radiotherapy can be expected. This hypothesis of course is of very speculative nature and its confirmation requires specific studies.

The incidence of imaging abnormalities after the treatment is relatively high in our series. Most authors report imaging abnormalities in about one third of the patients after treatment $[22,41,42]$. In a series reported by Hayhurst et al., it was approaching $50 \%$ of the patients, Nataf et al. reported even higher rate of parenchymal changes (44.8\% with T2 hyperintensity, $55.1 \%$ including T1 enhancement and necrosis) $[14,29]$. In our study, the incidence was $60 \%$ including one asymptomatic radiation necrosis. The doses applied were within the range reported in other series and did not appear to be the reason of frequent occurrence of imaging alterations. Most publications describe experiences with gamma knife treatment with dose usually specified on the $50 \%$ isodose. It means that maximal doses that could be responsible for initiation of radiation damage in the brain are twice as high as the prescribed ones. Utilization of a linear accelerator for treatment allows delivery of more homogeneous dose than in case of gamma knife, without hot spots characteristic for the latter and which theoretically could reduce the risk of radiation-induced damage. Our observations however do not support this assumption. The occurrence of imaging abnormalities also did not appear to be associated with the volume treated. In other studies, the irradiated volume was considered to be the main risk factor for subsequent imaging alterations [14]. Low number of patients treated precludes the possibility of identification of risk factors for radiation-induced imaging abnormalities. On the other hand, high signal intensity on post-treatment T2 MR images can be related to higher chance of obliteration [41]. High incidence of imaging alterations along with high obliteration rate in the current study could support this assumption. Late adverse effects of the treatment were not 
observed in our series. The occurrence of imaging alterations according to Yeon et al. was not associated with increased risk of neuropsychological sequelae [43]. The results of stereotactic irradiation of a large series of patients shown by Nicolato et al. confirm the safety of this kind of treatment as no adverse neuropsychological effects or intellectual deterioration were observed in this group of patients which is an argument in favor of noninvasive treatment of cerebral AVMs in children with stereotactic radiosurgery [30]. Nevertheless, the potential risk of decreased neurocognitive abilities after stereotactic irradiation, especially in children, should not be neglected. Consequently, relative high incidence of the imaging alterations in our opinion is the argument for long-term and meticulous observation after the treatment.

\section{Conclusions}

Due to small number of patients in our series, we do not attempt to draw general conclusions. It can be assumed that stereotactic radiosurgery is an effective method of treatment for pediatric AVMs. The patients require meticulous followup because of relative high incidence of radiation-induced imaging and potential risk of late adverse effects of the treatment. Further studies aiming at elucidation of radiobiological properties of AVMs in pediatric population are needed in order to establish the most efficient and safe fractionation regimen. Detailed analysis of the dose-response relationship on data pooled from other centers would probably shed more light on the actual alpha/beta ratio of pediatric AVMs and perhaps would allow for optimization of the treatment protocols.

Conflict of interest The authors declare that they have no conflict of interest.

Open Access This article is distributed under the terms of the Creative Commons Attribution License which permits any use, distribution, and reproduction in any medium, provided the original author(s) and the source are credited.

\section{References}

1. Abu-Salma Z, Nataf F, Ghossoub M, Schlienger M, Meder JF, Houdart E, Roux FX (2009) The protective status of subtotal obliteration of arteriovenous malformations after radiosurgery: significance and risk of hemorrhage. Neurosurgery 65:709-717. doi:10.1227/01.NEU.0000348546.47242.5D

2. Akakin A, Ozkan A, Akgun E, Koc DY, Konya D, Pamir MN, Kilic T (2010) Endovascular treatment increases but gamma knife radiosurgery decreases angiogenic activity of arteriovenous malformations. Neurosurgery 66:121-129. doi:10.1227/ 01.NEU.0000363154.88768.34

3. Akimoto H, Komatsu K, Kubota Y (2003) Symptomatic de novo arteriovenous malformation appearing 17 years after the resection of two other arteriovenous malformations in childhood: case report. Neurosurgery 52:228-232. doi:10.1227/00006123-200301000-00030

4. Al-Jarallah A, Al-Rifai MT, Riela AR, Roach ES (2000) Nontraumatic brain hemorrhage in children: etiology and presentation. J Child Neurol 15:284-289. doi:10.1177/088307380001500503

5. Altschuler EM, Lunsford LD, Coffey RJ, Bissonette DJ, Flickinger JC (1989) Gamma knife radiosurgery for intracranial arteriovenous malformations in childhood and adolescence. Pediatr Neurosci 15:53-61. doi:10.1159/000120443

6. Blom I, De Schryver EL, Kappelle LJ, Rinkel GJ, JennekensSchinkel A, Peters AC (2003) Prognosis of haemorrhagic stroke in childhood: a long-term follow-up study. Dev Med Child Neurol 45:233-239. doi:10.1017/S001216220300046X

7. Brown RD (2000) Simple risk predictions for arteriovenous malformation hemorrhage. Neurosurgery 46:1024. doi:10.1097/ 00006123-200004000-00055

8. Buis DR, Dirven CM, Lagerwaard FJ, Mandl ES, Lycklama A, Nijeholt GJ, Eshghi DS, van den Berg R, Baayen JC, Meijer OW, Slotman BJ, Vandertop WP (2008) Radiosurgery of brain arteriovenous malformations in children. J Neurol 255:551-560. doi:10.1007/s00415-008-0739-4

9. Celli P, Ferrante L, Palma L, Cavedon G (1984) Cerebral arteriovenous malformations in children: clinical features and outcome of treatment in children and in adults. Surg Neurol 22:43-49. doi:10.1016/0090-3019(84)90227-1

10. de Ribaupierre S, Rilliet B, Cotting J, Regli L (2008) A 10-year experience in paediatric spontaneous cerebral hemorrhage: which children with headache need more than a clinical examination. Swiss Med Wkly 138:59-69. doi:2008/05/smw-11958

11. Friedman JA, Pollock BE, Nichols DA (2000) Spontaneous development of a cerebral arteriovenous malformation documented in an adult by serial angiography. Case report. J Neurosurg 93:10581061. doi:10.3171/jns.2000.93.6.1058

12. Giroud M, Lemesle M, Madinier G, Manceau E, Osseby GV, Dumas R (1997) Stroke in children under 16 years of age. Clinical and etiological difference with adults. Acta Neurol Scand 96:401406. doi:10.1111/j.1600-0404.1997.tb00306.x

13. Halatsch ME, Rustenbeck HH, Jansen J (1997) Progression of arteriovenous malformation in moyamoya syndrome. Acta Neurochir (Wien) 139:82-85. doi:10.1007/BF01850873

14. Hayhurst C, Monsalves E, van Prooijen M, Cusimano M, Tsao M, Menard C, Kulkarni AV, Schwartz M, Zadeh G (2012) Pretreatment predictors of adverse radiation effects after radiosurgery for arteriovenous malformation. Int J Radiat Oncol Biol Phys 82:803808. doi:10.1016/j.ijrobp.2010.12.014

15. Humphreys RP, Hoffman HJ, Drake JM, Rutka JT (1996) Choices in the 1990 s for the management of pediatric cerebral arteriovenous malformations. Pediatr Neurosurg 25:277-285. doi:10.1159/000121140

16. Jordan LC, Hillis AE (2007) Hemorrhagic stroke in children. Pediatr Neurol 36:73-80. doi:10.1016/j.pediatrneurol.2006.09.017

17. Kader A, Goodrich JT, Sonstein WJ, Stein BM, Carmel PW, Michelsen WJ (1996) Recurrent cerebral arteriovenous malformations after negative postoperative angiograms. J Neurosurg 85:1418. doi:10.3171/jns.1996.85.1.0014

18. Kano H, Kondziolka D, Flickinger JC, Yang HC, Flannery TJ, Awan NR, Niranjan A, Novotny J, Lunsford LD (2012) Stereotactic radiosurgery for arteriovenous malformations, part 2: management of pediatric patients. J Neurosurg Pediatr 9:1-10. doi:10.3171/2011.9.PEDS10458

19. Klimo P Jr, Rao G, Brockmeyer D (2007) Pediatric arteriovenous malformations: a 15-year experience with an emphasis on residual and recurrent lesions. Childs Nerv Syst 23:31-37. doi:10.1007/ s00381-006-0245-x

20. Kocher M, Wilms M, Makoski HB, Hassler W, Maarouf M, Treuer H, Voges J, Sturm V, Müller RP (2004) Alpha/beta ratio for arteriovenous malformations estimated from obliteration rates after 
fractionated and single-dose irradiation. Radiother Oncol 71:109114. doi:10.1016/j.radonc.2003.08.005

21. Kondziolka D, Humphreys RP, Hoffman HJ, Hendrick EB, Drake JM (1992) Arteriovenous malformations of the brain in children: a forty year experience. Can J Neurol Sci 9:40-45

22. Kondziolka D, Kano H, Yang HC, Flickinger JC, Lunsford L (2010) Radiosurgical management of pediatric arteriovenous malformations. Childs Nerv Syst 26:1359-1366. doi:10.1007/s00381-010-1207-x

23. Lindqvist M, Karlsson B, Guo WY, Kihlström L, Lippitz B, Yamamoto M (2000) Angiographic long-term follow-up data for arteriovenous malformations previously proven to be obliterated after gamma knife radiosurgery. Neurosurgery 46:803-808. doi:10.1097/00006123-200004000-00006

24. Loh Y, Duckwiler GR, Investigators OT (2010) A prospective, multicenter, randomized trial of the Onyx liquid embolic system and $N$-butyl cyanoacrylate embolization of cerebral arteriovenous malformations. Clinical article. J Neurosurg 113:733-741. doi:10.3171/2010.3.JNS09370

25. Lunsford LD, Kondziolka D, Flickinger JC, Bissonette DJ, Jungreis CA, Maitz AH, Horton JA, Coffey RJ (1991) Stereotactic radiosurgery for arteriovenous malformations of the brain. J Neurosurg 75:512-524. doi:10.3171/jns.1991.75.4.0512

26. Lv X, Wu Z, Jiang C, Li Y, Yang X, Zhang Y, Zhang N (2011) Complication risk of endovascular embolization for cerebral arteriovenous malformation. Eur J Radiol 80:776-779. doi:10.1016/ j.ejrad.2010.09.024

27. Meyer PG, Orliaguet GA, Zerah M, Charron B, Jarreau MM, Brunelle F, Laurent-Vannier A, Carli PA (2000) Emergency management of deeply comatose children with acute rupture of cerebral arteriovenous malformations. Can J Anaesth 47:758-766. doi:10.1007/BF03019478

28. Mirza B, Mønsted A, Harding J, Ohlhues L, Roed H, Juhler M (2010) Stereotactic radiotherapy and radiosurgery in pediatric patients: analysis of indications and outcome. Childs Nerv Syst 26:1785-1793. doi:10.1007/s00381-010-1134-x

29. Nataf F, Schlienger M, Lefkopoulos D, Merienne L, Ghossoub M, Foulquier JN, Deniaud-Alexandre E, Mammar H, Meder JF, Turak B, Huart J, Touboul E, Roux FX (2003) Radiosurgery of cerebral arteriovenous malformations in children: a series of 57 cases. Int J Radiat Oncol Biol Phys 57:184-195. doi:10.1016/S0360-3016(03)00445-0

30. Nicolato A, Lupidi F, Sandri MF, Foroni R, Zampieri P, Mazza C, Maluta S, Beltramello A, Gerosa M (2006) Gamma knife radiosurgery for cerebral arteriovenous malformations in children/adolescents and adults. Part I: differences in epidemiologic, morphologic, and clinical characteristics, permanent complications, and bleeding in the latency period. Int J Radiat Oncol Biol Phys 64:904-913. doi:10.1016/j.ijrobp.2005.07.983

31. Nicolato A, Lupidi F, Sandri MF, Foroni R, Zampieri P, Mazza C, Pasqualin A, Beltramello A, Gerosa M (2006) Gamma knife radiosurgery for cerebral arteriovenous malformations in children/adolescents and adults. Part II: differences in obliteration rates, treatment-obliteration intervals, and prognostic factors. Int J Radiat Oncol Biol Phys 64:914-921. doi:10.1016/j.ijrobp.2005.09.013

32. Pan DH, Kuo YH, Guo WY, Chung WY, Wu HM, Liu KD, Chang YC, Wang LW, Wong TT (2008) Gamma knife surgery for cerebral arteriovenous malformations in children: a 13-year experience. J Neurosurg Pediatr 1:296-304. doi:10.3171/PED/ 2008/1/4/296

33. Pollock BE, Flickinger JC (2008) Modification of the radiosurgerybased arteriovenous malformation grading system. Neurosurgery 63:239-243. doi:10.1227/01.NEU.0000315861.24920.92

34. Puzzilli F, Salvati M, Bristot R, Raco A, Ruggeri A, Bastianello S, Lunardi P (1997) Spontaneous cerebellar haemorrhages in childhood. Childs Nerv Syst 13:601-603. doi:10.1007/ s003810050149

35. Reig AS, Rajaram R, Simon S, Mericle RA (2010) Complete angiographic obliteration of intracranial AVMs with endovascular embolization: incomplete embolic nidal opacification is associated with AVM recurrence. J Neurointerv Surg 2:202-207. doi:10.1136/jnis.2009.001636

36. Reyns N, Blond S, Gauvrit JY, Touzet G, Coche B, Pruvo JP, Dhellemmes P (2007) Role of radiosurgery in the management of cerebral arteriovenous malformations in the pediatric age group: data from a 100-patient series. Neurosurgery 60:268-276. doi:10.1227/01.NEU.0000249277.72063.BD

37. Shin M, Kawamoto S, Kurita H, Tago M, Sasaki T, Morita A, Ueki K, Kirino T (2002) Retrospective analysis of a 10-year experience of stereotactic radio surgery for arteriovenous malformations in children and adolescents. J Neurosurg 97:779-784. doi:10.3171/ jns.2002.97.4.0779

38. Sonstein WJ, Kader A, Michelsen WJ, Llena JF, Hirano A, Casper D (1996) Expression of vascular endothelial growth factor in pediatric and adult cerebral arteriovenous malformations: an immunocytochemical study. J Neurosurg 85:838-845. doi:10.3171/ jns. 1996.85.5.0838

39. Sure U, Butz N, Siegel AM, Mennel HD, Bien S, Bertalanffy H (2001) Treatment-induced neoangiogenesis in cerebral arteriovenous malformations. Clin Neurol Neurosurg 103:29-32. doi:10.1016/S0303-8467(01)00112-3

40. Takeshita M, Kagawa M, Izawa M, Kitamura K (1986) Hemorrhagic stroke in infancy, childhood, and adolescence. Surg Neurol 26:496-500. doi:10.1016/0090-3019(86)90263-6

41. Van den Berg R, Buis DR, Lagerwaard FJ, Nijeholt GJ Là, Vandertop WP (2008) Extensive white matter changes after stereotactic radiosurgery for brain arteriovenous malformations: a prognostic sign for obliteration. Neurosurgery 63:1064-1069. doi:10.1227/ 01.NEU.0000330413.73983.02

42. Van Rooij WJ, Jacobs S, Sluzewski M, van der Pol B, Beute GN, Sprengers ME (2012) Curative embolization of brain arteriovenous malformations with onyx: patient selection, embolization technique, and results. AJNR Am J Neuroradiol. doi:10.3174/ ajnr.A2947

43. Yeon JY, Shin HJ, Kim JS, Hong SC, Lee JI (2011) Clinicoradiological outcomes following gamma knife radiosurgery for pediatric arteriovenous malformations. Childs Nerv Syst 27:1109-1119. doi:10.1007/s00381-011-1401-5

44. Zabel-du Bois A, Milker-Zabel S, Huber P, Schlegel W, Debus J (2006) Pediatric cerebral arteriovenous malformations: the role of stereotactic linac-based radiosurgery. Int J Radiat Oncol Biol Phys 65:1206-1211. doi:10.1016/j.ijrobp.2006.01.041 